\title{
Quantification of the Dental Morphology of Orangutans
}

\author{
P. Nambiar, ${ }^{1}$ J. John, ${ }^{1}$ Samah M. Al-Amery, ${ }^{1}$ K. Purmal, ${ }^{2}$ W. L. Chai, \\ W. C. Ngeow, ${ }^{3}$ N. H. Mohamed, ${ }^{1}$ and S. Vellayan ${ }^{4}$ \\ ${ }^{1}$ Department of Diagnostic and Integrated Dental Practice, Faculty of Dentistry, University of Malaya, 50603 Kuala Lumpur, Malaysia \\ ${ }^{2}$ School of Dental Sciences, Universiti Sains Malaysia, 16150 Kubang Kerian, Kelantan, Malaysia \\ ${ }^{3}$ Department of Oral and Maxillofacial Surgery, Faculty of Dentistry, University of Malaya, 50603 Kuala Lumpur, Malaysia \\ ${ }^{4}$ Faculty of Pharmacy, Universiti Teknologi MARA, Puncak Alam, 42300 Kuala Selangor, Selangor, Malaysia
}

Correspondence should be addressed to J. John; drjacob@um.edu.my

Received 28 August 2013; Accepted 23 September 2013

Academic Editors: F. Sfondrini, Ü. Tan, and K. H. Zawawi

Copyright (C) 2013 P. Nambiar et al. This is an open access article distributed under the Creative Commons Attribution License, which permits unrestricted use, distribution, and reproduction in any medium, provided the original work is properly cited.

\begin{abstract}
Orangutans are believed to have close biological affinities to humans. Teeth being the hardest tissue provide useful information on primate evolution. Furthermore, knowledge of the pulp chamber and root canal morphology is important for dental treatment. A female Bornean orangutan and a Sumatran male orangutan skull were available for this study. Both of their dentitions, comprising 50 teeth, were scanned employing the cone-beam computed tomography for both metrical and nonmetrical analyses. Measurements included tooth and crown length, root length, enamel covered crown height, root canal length (posterior teeth), length of pulpal space (anterior teeth), and root canal width. Nonmetrical parameters included number of canals per root, number of foramina in each root, and root canal morphology according to Vertucci's classification. It was found that the enamel covered crown height was the longest in the upper central incisors although the canine was the longest amongst the anterior teeth. Both the upper premolars were three-rooted while the lower second premolar of the Sumatran orangutan was two-rooted, with two foramina. The mandibular lateral incisors of the Bornean orangutan were longer than the central incisors, a feature similar to humans. In addition, secondary dentine deposition was noticed, a feature consistent with aged humans.
\end{abstract}

\section{Introduction}

Orangutans (Pongo spp.), the Southeast Asian great apes, are interesting primates considered to be the closest living relative to human beings. Orangutans have a minimum of 28 distinctive physical characteristics similar to humans but only two characteristics with chimpanzees and seven with gorillas [1]. Most researchers recognize two separate subspecies, Pongo abelii in Sumatra and Pongo pygmaeus in Borneo. Current studies prove that the two taxonomic groups are geographically isolated for 10,000-15,000 years [2].

Several previous studies [2, 3] have listed some general external characteristics to differentiate the two species. Bornean orangutan has been described as having hair colour ranging from red to deep maroon or blackish brown. In contrast, Sumatran orangutan's hair colour is lighter, rusty red, or light cinnamon. However, there is an extreme form of Sumatran orangutan which has dark-haired colour similar to the Bornean [4], indicating the need for caution in the use of colour as a taxonomic marker. In addition, the variation in the dental morphology and cranial measurements within Bornean orangutan is greater than or equal to the variation between Bornean and Sumatran orangutan [5]. Comparable differences in the cranial measurements were also observed within the Bornean population [6].

The variations between the Bornean and Sumatran may be ontogenetic responses to different environments they reside in [4]. Several researchers have established the relationship between dental enamel thickness and their diet. Hardobject feeders have thicker enamel than soft-object feeders [7]. The Bornean [8] showed strong mandibles with high resistance to teeth fractures during the mastication process. This difference in the strength of mandible was due to the nature of the food consumed by the different species. This theory is supported by the finding [9] that Bornean orangutan often consumes more tough food than the Sumatran orangutan, which feeds more on ripe fruit available throughout the year. Although the male orangutan consumes harder 
food, both Bornean and Sumatran females have been noted to consume more bark than males [10].

The enamel thickness indices between orangutan maxillary and mandibular teeth show similar pattern to other great apes and humans [11] with the average thickness increasing from the anterior to the posterior teeth. However, orangutan shows unusual enamel thickness in their central incisors. This thickness is related to bark gouging or incisal biting of the mechanically demanding foods [8]. The maxillary molars tend to be broader in a buccolingual dimension compared to the mandibular molars, providing it with the wide crosssectional area required [12]. Both orangutan and human dentition are well known to be dimorphic, where the males' exhibit larger dentine cores and therefore have larger teeth [13]. In addition, the orangutan male exhibits greater or equal enamel cap area value compared to the female [14].

Tooth morphology information is useful for understanding human and primate evolution. As teeth are the most calcified tissue, fossilized teeth have durable postmortem preservation and have been used to study the evolutionary linkage of human and other primates. It is also reported [15] that signs of dental diseases in primates can be misleading as the proximity of the dentition to many important structures may cause bacterial infections of the inner ear, sinuses, and possibly the eyes. Moreover, knowledge of root canal morphology is important for both surgical and nonsurgical endodontic therapies. A cone-beam computed tomography (CBCT) machine is a perfect scanning machine to determine the root canal system in different planes simultaneously [16]. Recognition of variations in root canal anatomy is an essential prerequisite for successful endodontic diagnosis and treatment. Besides the main advantage of low radiation dosage when compared to the cumbersome medical multidetector/helical CT, CBCT is capable of measuring dental structures in different direction wherein the images are undistorted and exact in size [17].

At present little is known about root canal morphology and size of orangutan teeth. Two of the authors (Purmal and Nambiar) successfully treated a Bornean orangutan's carious canine tooth [18], possibly caused by an unusual defective enamel development. This research was therefore undertaken to understand the dental anatomy and pulpal morphology of the two different orangutans, Pongo abelii and Pongo pygmaeus, and to make some comparisons to human dentition.

\section{Materials and Methods}

2.1. Imaging with CBCT. Two well-preserved skulls were obtained with permission from the National Zoo, located at Kuala Lumpur, Malaysia. One was a Bornean female with near full dentition (Figure 1(a)) while the other was a Sumatran male with a partial dentition (Figure 1(b)). Scanning of the dentition was performed employing the Kodak 9000 3D CBCT extraoral imaging system (Carestream Health, Inc.) at the Oral and Maxillofacial Imaging Division, Faculty of Dentistry, University of Malaya. This machine recorded the scanned volume at a field-of-view (FOV) size of $5 \times 3.8 \mathrm{~cm}$ with a spatial resolution of $76 \mathrm{~mm}$ and grey resolution of 14 bits. An advantage of this CBCT machine is that the images can be studied by using different representations (multiplanar reformation, and 3D surface rendering). These various images were reconstructed from the CBCT data using the proprietary Kodak Dental Imaging Software 3D module version 3.1.9. This study examined 50 teeth obtained from imaging the two orangutans' skulls, thirty-two in the Bornean orangutan and eighteen in the Sumatran orangutan (Table 1).

2.2. Metrical Measurements. Several measurements (Figure 2) were performed to study the size of orangutan teeth and pulpal canal. A method of measuring the teeth needed to be devised as the orangutan teeth were different from human. In human, the crown was the enamel covered portion while the length of the root could be measured from the cementenamel junction to the apex of the roots. As the orangutan had an excessive length on the mesial portion of its tooth compared to the distal, a definite method of measurement was required. Tooth length (Figure 2(a)) was measured from occlusal plane surface (highest cusp tip tips as the reference point points) to the apical foramen of the longest root. Both the crown height and its related root length were measured after a line was drawn at the level of the bi/trifurcating roots in the posterior teeth. This line was drawn parallel to the occlusal plane of the particular tooth. The root length (Figure 2(b)) was measured as the distance from this line to the apex of the root. The crown length (Figure 2(c)) was measured as the distance from the occlusal surface to the line at the level of the bifurcation area. Root canal width (Figure 2(d)) was measured at three levels: (i) at the level of the root canal orifice; (ii) visible canal at the root apex; and (iii) at the midpoint between root canal orifice and the visible canal at the root apex. Additional measurement was performed to determine the area covered by enamel (Figure 2(e)). This was measured as the distance from the occlusal cuspal tip to the level of the endpoint of the enamel covered crown. The actual root canal length (Figure 2(f)) was measured from the level of the root canal orifice to apical foramen, following closely the curvature of the root canal. The anterior teeth are all singlerooted. Both the tooth length and the enamel covered area were measured following the same method as that for the posterior teeth. Crown length, root length, and root canal length were omitted because of the absence of the bifurcation of the roots. The length of the pulp space was measured as a distance from the maximum point of pulp chamber occlusally to the maximum point of the visible root canal apically.

2.3. Nonmetrical Observations. Additional investigations were conducted on the axial images, especially the number of the apical foramina for each root and number of canals in each root. This view was also important in confirming the root canal morphology according to Vertucci's classification (Figure 3). Data was entered and analyzed using SPSS 12.01 for windows (SPSS Inc., Chicago, USA).

\section{Results}

Tables 2 and 3 summarize the results of the various metrical measurements in this study. It was noticed that the height of the crown covered by enamel in the maxillary anterior teeth 
TABLE 1: Distribution of the orangutan teeth employed in this study.

\begin{tabular}{lcccccccccc}
\hline Orangutan & & $\mathrm{I}_{1}$ & $\mathrm{I}_{2}$ & $\mathrm{C}$ & $\mathrm{PM}_{1}$ & $\mathrm{PM}_{2}$ & $\mathrm{M}_{1}$ & $\mathrm{M}_{2}$ & $\mathrm{M}_{3}$ & $\mathrm{Total}_{2}$ \\
\hline \multirow{2}{*}{ Bornean } & Max. & 2 & 2 & 2 & 2 & 2 & 2 & 2 & 2 & 16 \\
& Mand. & 2 & 2 & 2 & 2 & 2 & 2 & 2 & 16 \\
\hline \multirow{2}{*}{ Sumatran } & Max. & 2 & 2 & 2 & 2 & 2 & 0 & 0 & 0 \\
& Mand. & 0 & 2 & 2 & 2 & 1 & 1 & 0 & 0 & 8 \\
\hline
\end{tabular}

Max.: maxillary; Mand.: mandibular; $\mathrm{I}_{1}$ : central incisor; $\mathrm{I}_{2}$ : lateral incisor; $\mathrm{C}$ : canine; $\mathrm{PM}_{1}$ : first premolar; $\mathrm{PM}_{2}$ : second premolar; $\mathrm{M}_{1}$ : first molar; $\mathrm{M}_{2}$ : second molar; $\mathrm{M}_{3}$ : third molar.

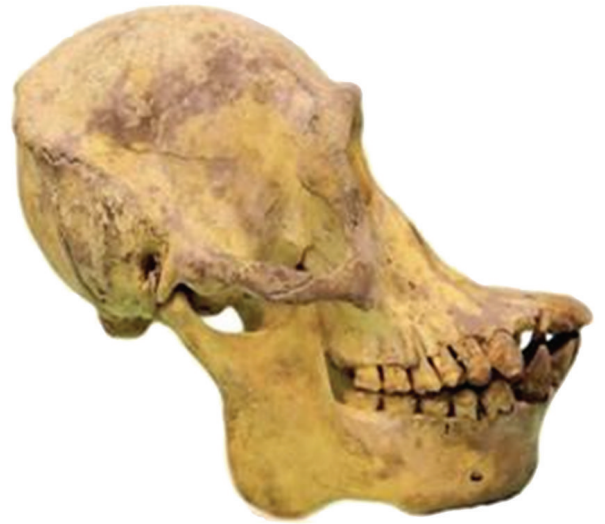

(a1)

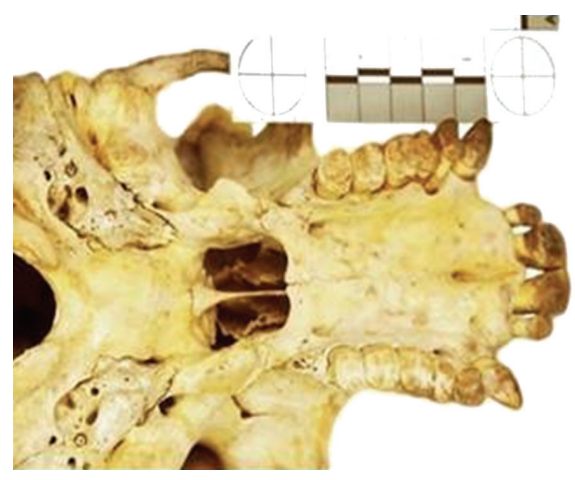

(b1)

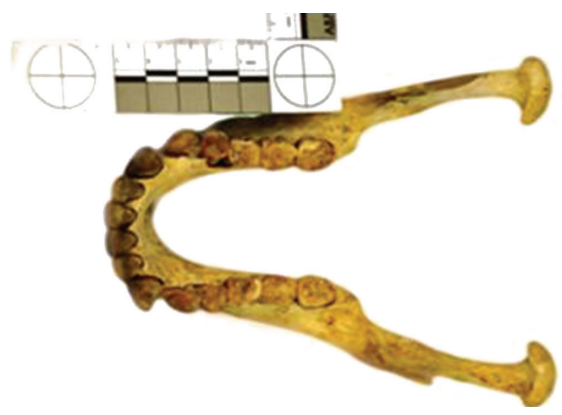

$(\mathrm{c} 1)$

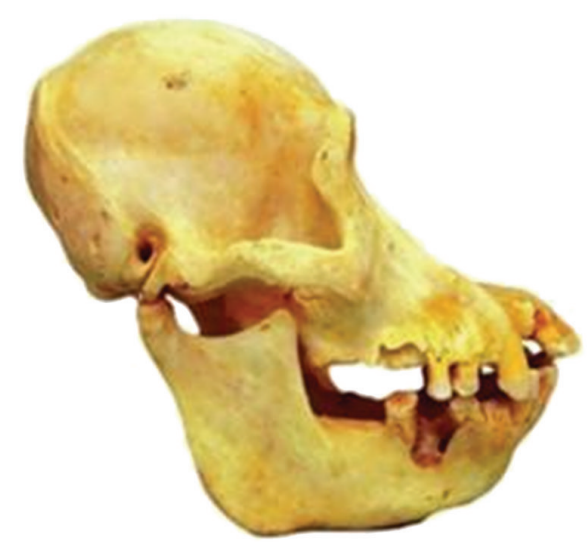

(a2)

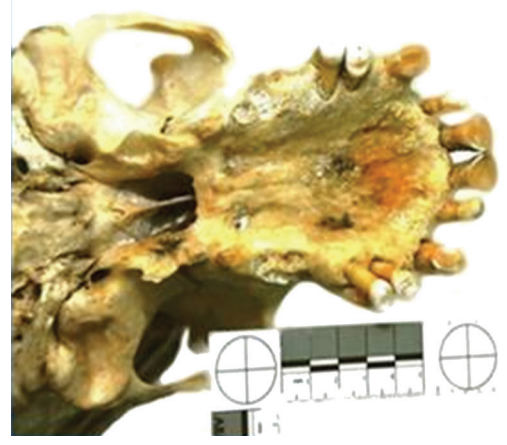

(b2)

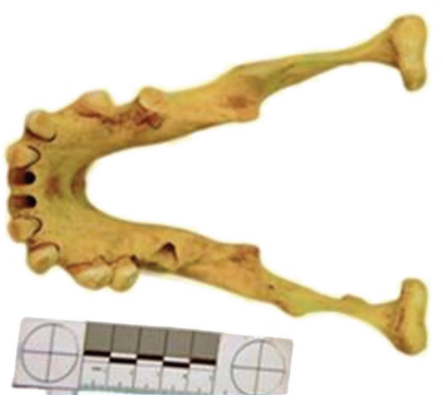

(c2)

FIGURE 1: (a1) Bornean orangutan skull; (b1) Bornean orangutan maxillary arch; (c1) Bornean orangutan mandible arch; (a2) Sumatran orangutan skull; (b2) Sumatran orangutan maxillary arch; (c2) Sumatran orangutan mandibular arch. 
TABLE 2: Anterior teeth measurements.

\begin{tabular}{|c|c|c|c|c|c|c|c|}
\hline & & \multicolumn{4}{|c|}{ Bornean orangutan } & \multicolumn{2}{|c|}{ Sumatran orangutan } \\
\hline & & $\mathrm{TL}$ & $\mathrm{ECCH}$ & LPS & $\mathrm{TL}$ & $\mathrm{ECCH}$ & LPS \\
\hline \multirow{2}{*}{ Max. $\mathrm{I}_{1}$} & $\mathrm{R}$ & 35.6 & 12.2 & 32.1 & 34.6 & 11.3 & 31 \\
\hline & $\mathrm{L}$ & 35.3 & 13.8 & 31.9 & 33.6 & 10.5 & 29.8 \\
\hline \multirow{2}{*}{ Max. $\mathrm{I}_{2}$} & $\mathrm{R}$ & 29.2 & 7.1 & 24.8 & 30.6 & 8.6 & 25.4 \\
\hline & $\mathrm{L}$ & 29.9 & 8.4 & 25.5 & 30.9 & 8.4 & 26.5 \\
\hline \multirow{2}{*}{ Max. C } & $\mathrm{R}$ & 39.9 & 8.9 & 34.5 & 45.7 & 8.1 & 38.2 \\
\hline & $\mathrm{L}$ & 39.6 & 8.9 & 34.6 & 43.7 & 8.2 & 37.7 \\
\hline \multirow{2}{*}{ Mand. $\mathrm{I}_{1}$} & $\mathrm{R}$ & 31.2 & 10.8 & 27.9 & $\mathrm{~ms}$ & $\mathrm{~ms}$ & $\mathrm{~ms}$ \\
\hline & $\mathrm{L}$ & 32.2 & 11.2 & 26.9 & $\mathrm{~ms}$ & $\mathrm{~ms}$ & $\mathrm{~ms}$ \\
\hline \multirow{2}{*}{ Mand. $\mathrm{I}_{2}$} & $\mathrm{R}$ & 33.1 & 9.8 & 28.6 & 33.8 & 7.5 & 29.7 \\
\hline & $\mathrm{L}$ & 33.6 & 10.5 & 29.2 & 32.9 & 7.7 & 31.7 \\
\hline \multirow{2}{*}{ Mand. C } & $\mathrm{R}$ & 42.7 & 12.8 & 39.4 & 42.9 & 10.4 & 38.3 \\
\hline & $\mathrm{L}$ & 44.9 & 13.3 & 40.9 & 45.4 & 12.2 & 40.6 \\
\hline
\end{tabular}

TL: tooth length; ECCH: enamel covered crown height; LPS: length of the pulp space; R: right; L: left; ms: missing tooth.

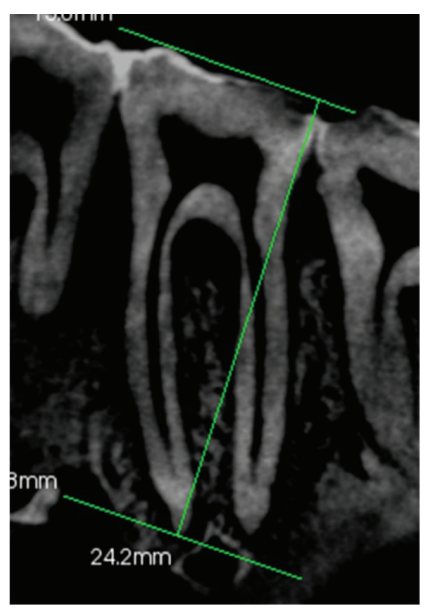

(a)

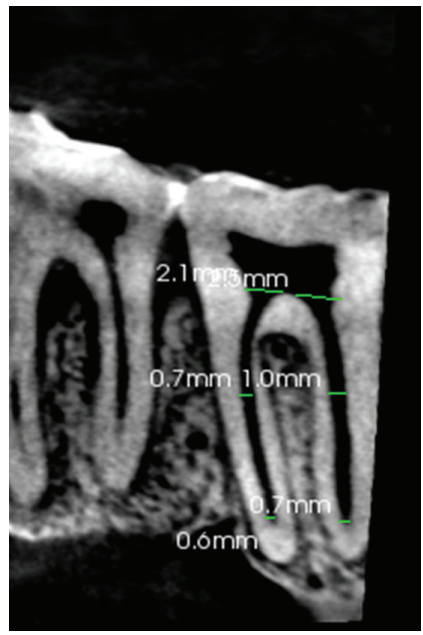

(d)

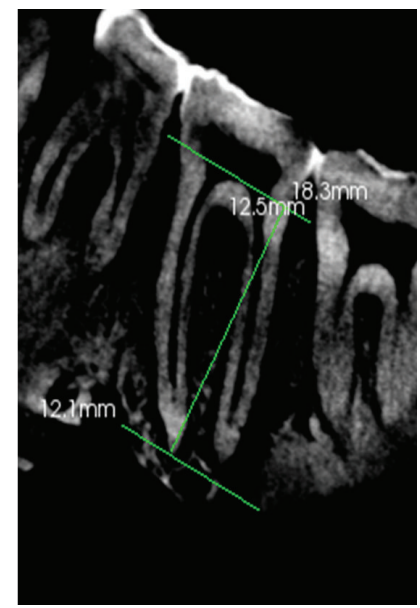

(b)

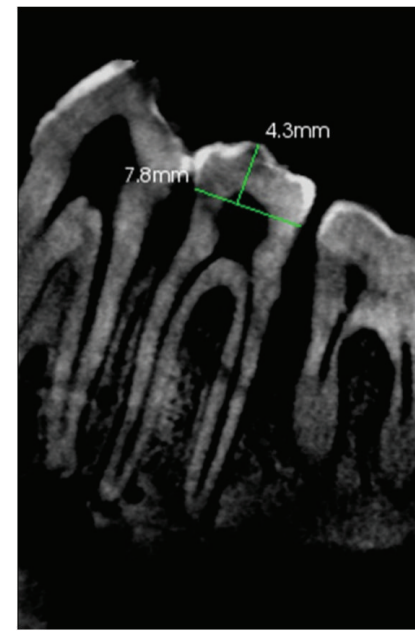

(e)

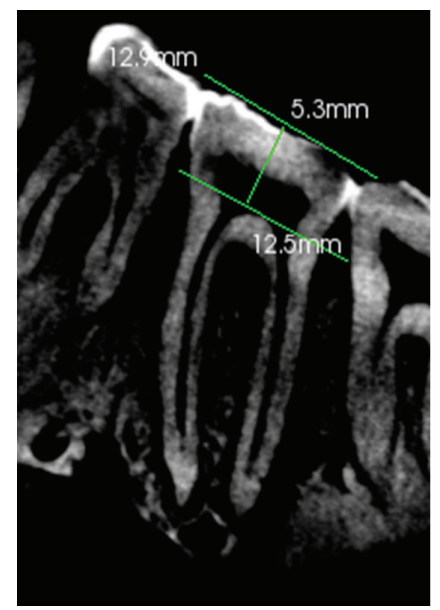

(c)

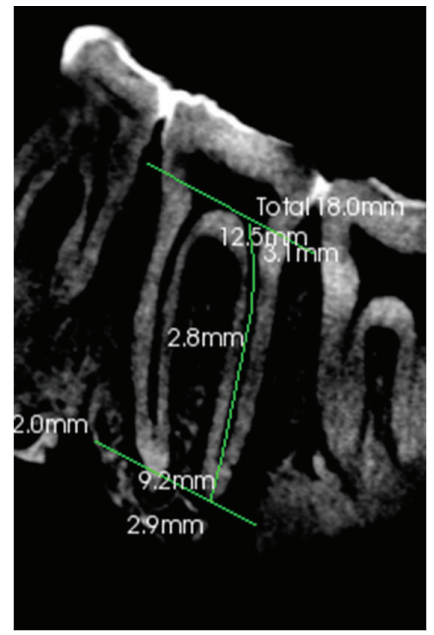

(f)

FIGURE 2: (a) Total tooth length; (b) root length; (c) crown length; (d) root canal width; (e) enamel covered crown length; (f) root canal length. 
TABLE 3: Posterior teeth measurements.

(a)

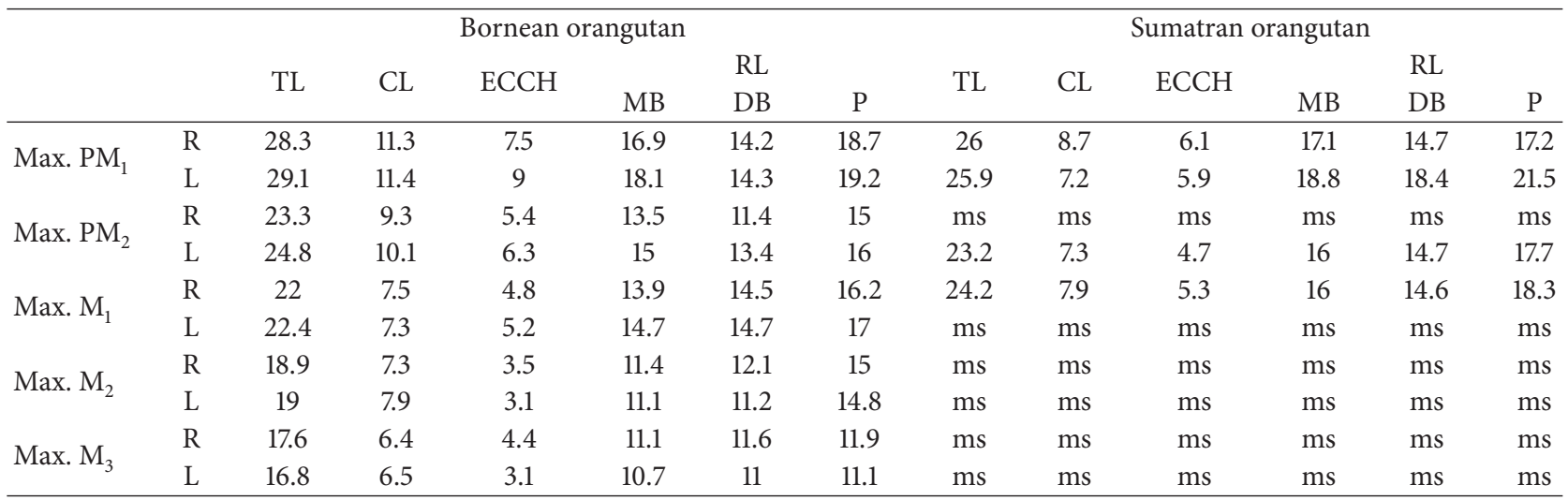

(b)

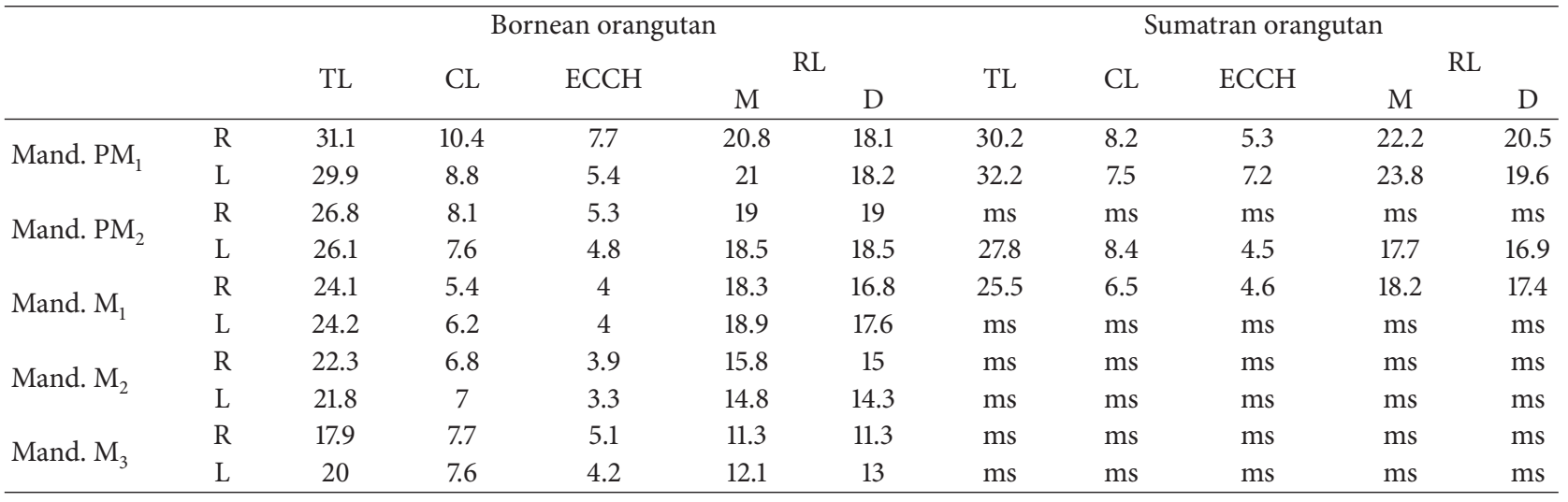

R: right; L: left; TL: tooth length; CL: Crown length; ECCH: enamel covered area; LPS: length of the pulp space; RL: root length; MB: mesiobuccal root; DB: distobuccal root; P: palatal root; M: mesial root; DB: distal root; ms: missing tooth.

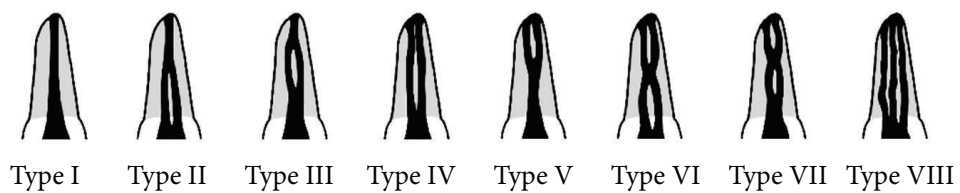

FIGURE 3: Vertucci's classification of root canal morphology adapted from Vertucci [26].

was larger in the Bornean orangutan. It ranged between 7.1 and $13.8 \mathrm{~mm}$, while in the Sumatran's skull it ranged between 8.1 and $11.3 \mathrm{~mm}$. An interesting finding is that the enamel covered crown height $(\mathrm{ECCH})$ of the central incisors was the longest despite the canines being the longest anterior teeth. In contrast, this feature was not observed on the lower anterior teeth. The longest ECCH was found on the mandibular caninet, which was also the longest mandibular anterior tooth. In addition it was observed that the Sumatran orangutan had longer maxillary canines than the Bornean female, with a difference of $5.8 \mathrm{~mm}$ and $4.1 \mathrm{~mm}$ for the right and left canines, respectively. The mandibular canines did not show any significant differences between the two species (Table 2).

According to the measurements of the posterior teeth, the maxillary first premolar was longer in the Bornean skull than in the Sumatran skull with a length of $28.3 \mathrm{~mm}$ and $29.1 \mathrm{~mm}$ for right and left side, respectively, while the corresponding teeth of the Sumatran male measured $26 \mathrm{~mm}$ and $25.9 \mathrm{~mm}$. Unlike humans, the orangutans had unique premolars as they were three-rooted. The palatal roots were longer than the other roots, which were the mesiobuccal and distobuccal roots. The maxillary molar root system also demonstrated a similar pattern. The lower dentition exhibited mesial roots longer than the distal roots; this variation in the root length was clearly seen in the Sumatran orangutan with a range of $17.7-23.8 \mathrm{~mm}$ for the mesial root and $16.9-20.5 \mathrm{~mm}$ for distal root (Table 3).

Table 4 shows that the maximum width of the root canal was at the level of the root canal orifice of each root. Subsequently, the canal was tapering towards the apex. Interestingly the palatal root canal width was the widest as 

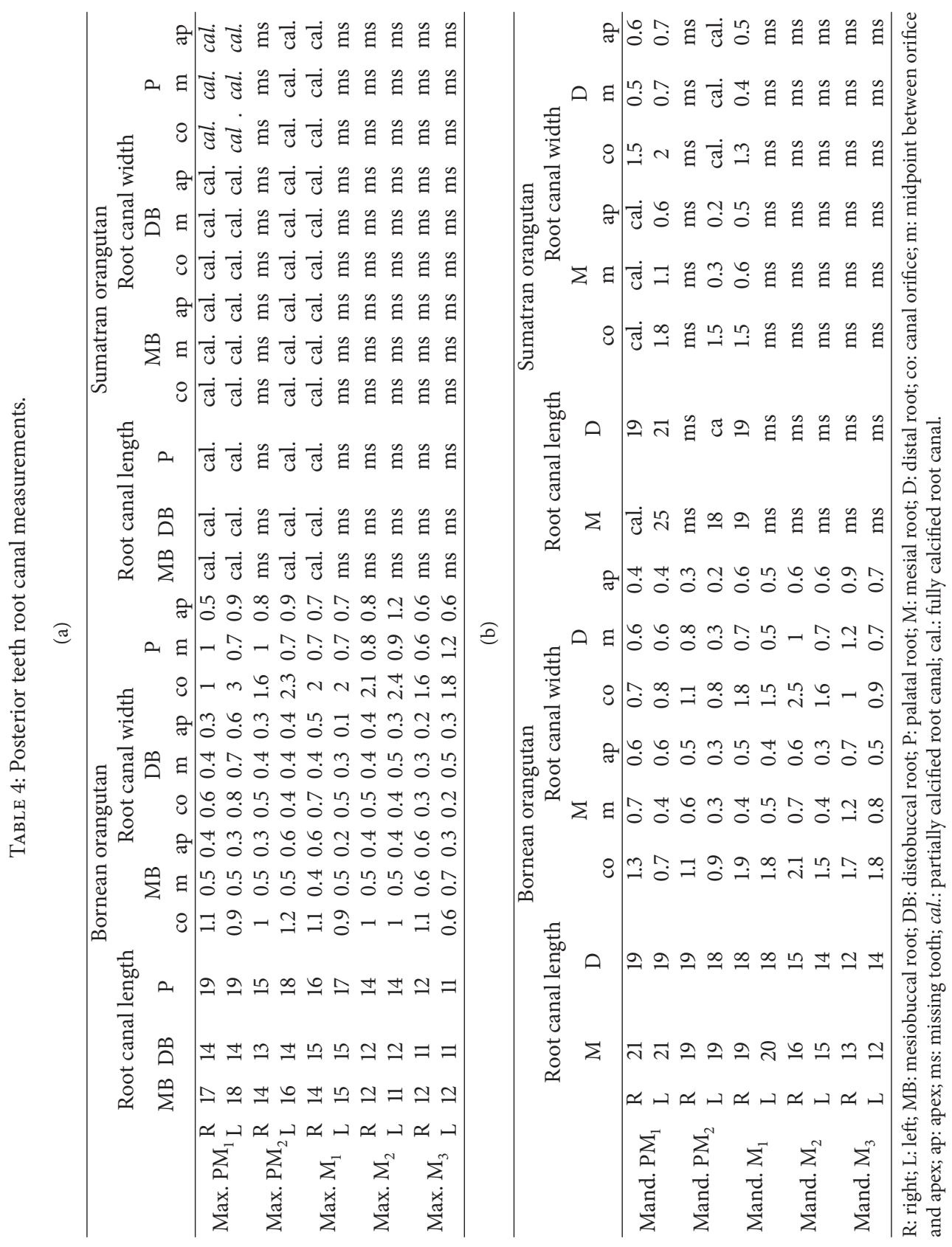


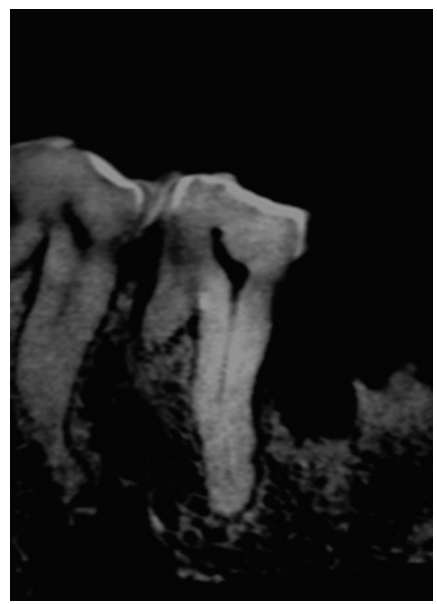

(a1)

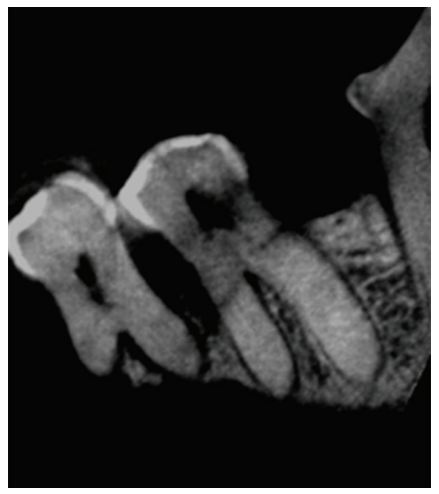

(b1)

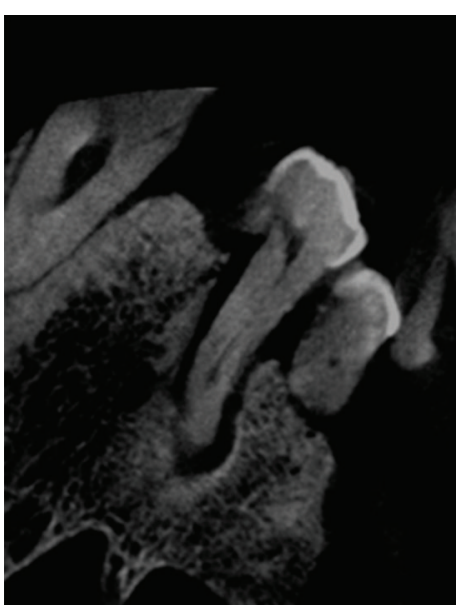

(a2)

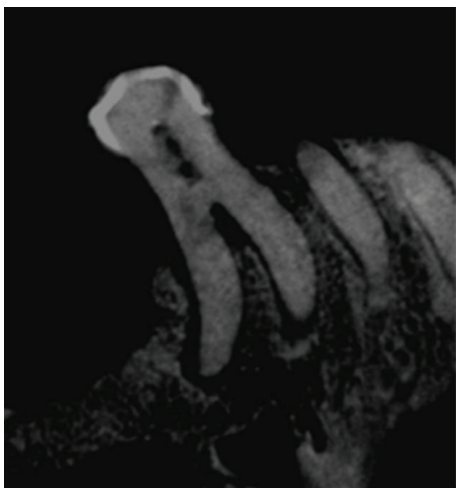

(b2)

FIgure 4: (a1 and a2) Partially calcified teeth; (b1 and b2) fully calcified or completely obliterated teeth.

well as the longest. The Sumatran male was probably the older between the two as it had more missing teeth as well as partially obliterated root canals. The pattern of calcification looks similar to humans, whereby the pulp chamber and root canal become reduced as age advances (Figure 4).

The nonmetrical parameters explored the number of canals per root, number of foramina detected in each root, and Vertucci's classification of root canal variations. In general, all the teeth have one canal with one apical foramen per root. However, one exception was noticed in the mesial root of the lower left second premolar of the Sumatran orangutan, where there were two root canals with corresponding two foramina (Figure 5(a)). Unfortunately only the left second premolar was available for scanning as the right corresponding tooth was missing. Apart from this variation it was noticed that Bornean orangutan showed type III Vertucci's classification in the lower lateral incisors (Figure 5(b1-b3)).

\section{Discussion}

Orangutans, coming from the family of great apes and being native of the rainforests of Borneo and Sumatra, have many similarities as well as differences in their dentition with humans. The most unique feature observed among the two orangutans from this study was the number of roots in the first and second premolar in both jaws. Maxillary first and second premolars have three roots, while the mandible premolars have only two. Among human beings, the maxillary first premolar has two roots and the second premolar has only one, while in the mandibular jaw, the first and second premolar are with only one root [19]. It is also interesting to note the difference in root canal morphology in orangutans as compared to human dentition. In human beings, $64.4 \%$ of the mandibular first molars have two canals [20]. This was however not noticed in both the orangutans, where the mandibular first molar showed only one canal in each root. Moreover, the Sumatran orangutan exhibited two canals in the mesial root of the mandibular second premolar, unlike the Bornean orangutan. This difference could possibly be due to variations between the two species or maybe even a gender difference.

The average human being maxillary central incisor length is $23.5 \mathrm{~mm}$, with a crown length of $10.5 \mathrm{~mm}$ and root length of $13 \mathrm{~mm}$ [20]. In comparison, the maxillary central incisors 


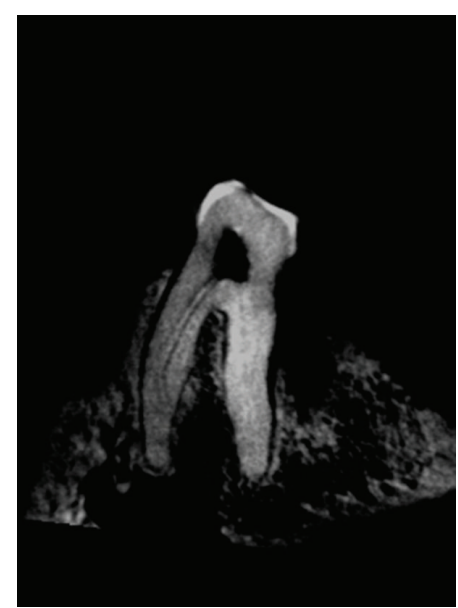

(a)

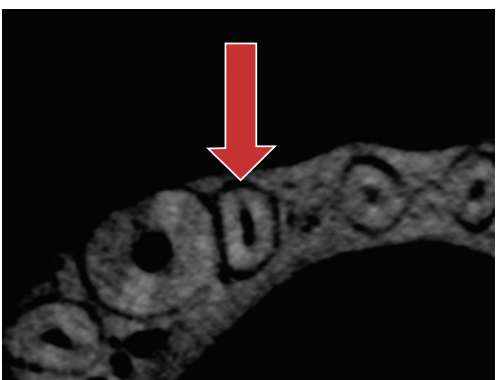

(b1)

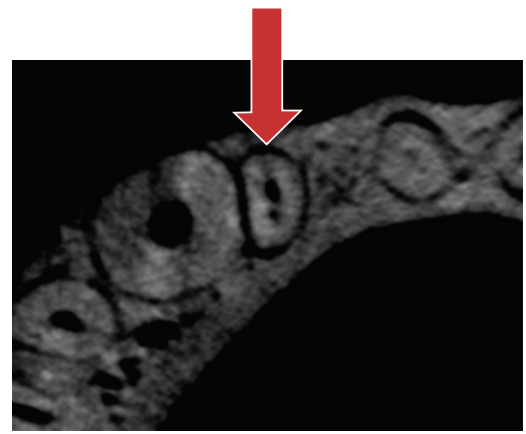

(b2)

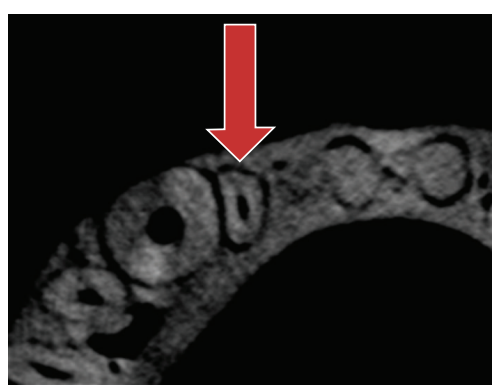

(b3)

(b)

FIGURE 5: (a) Mesial root of the lower left second premolar of the Sumatran orangutan showing two root canals with corresponding two foramina; (b1, b2, and b3) a series of axial views of the lower lateral incisor (shown by arrow) of Bornean orangutan showing type III canal morphology of Vertucci's classification, where the canal begins as one, branches into 2 in the middle, and unites to become one.

of the orangutans were significantly longer, whereby the length of the Bornean and Sumatran orangutans was 35.6 and $34.6 \mathrm{~mm}$, respectively, with larger enamel covered surface. This could be explained due to the variation in the diet pattern, where the orangutan would need stronger anteriors and thicker enamel for gouging barks of trees.

In ape dentitions, the common molar size sequence is assumed to be $M_{3}>M_{2}>M_{1}$, and this sequence is held in contrast to the assumed human sequence, $M_{1}>M_{2}>M_{3}$ [21]. In this study, it is evident that the teeth length values decreased from the first premolar to the third molar in both the arches. This is quite typical in human beings where the 1st tooth of each class of teeth is the least variable and exhibits the strongest characteristics observed in that class of teeth, with the exception of the lower anterior incisors. It is noticed that even in the Bornean orangutan the lower lateral incisors were indeed longer than the central incisor, a finding similar to humans and as reported by Gingerich and Schoeninger [22].

The molars exhibited a root canal length between 11 and $19.5 \mathrm{~mm}$. The large variations in their length are due to calcification of the roots as both the orangutans could have died at an advanced age. Similar to human the most conspicuous change is the decreasing volume of the pulp chamber and root canal brought about by continuous secondary dentine formation. In old teeth, the root canal is often no more than a thin channel and in certain occasions appears almost obliterated completely [23]. This is also evident in these orangutans where the continuous constrictions of the pulpal cavity cause reduction of the vascular supply to the pulp, thereby causing age related changes on the tooth. Furthermore, some of the root canals of the Sumatran orangutan teeth were partially calcified while some were completely obliterated (Figure 4). This indicated that the animal was probably at an advanced age when it died. It is estimated [24] that orangutans can live more than 40 years in the wild and between 50 and 60 years in captivity. Another similarity between orangutan and human was in length of the palatal root in the maxillary molars where the palatal root was longer than mesiobuccal and distobuccal roots with even the palatal root in the maxillary premolars following the same pattern.

Veterinary dentists must be aware that there are many pathways the root canals take to reach the apex. The pulp canal system may be complex and canals may branch, divide, and rejoin. Caution must however be expressed as it is difficult to determine the number of canals in each root employing either the coronal or sagittal images as there were superimposition of these canals $[25,26]$. In these cases, 
a search employing the axial view becomes useful. The lower lateral incisor of the Bornean orangutan in this study showed type III Vertucci's classification which was surprisingly unique (Figures 5(b1-b3)).

\section{Conclusions}

Variations in the morphology of teeth amongst the orangutans have both genetic and environmental influences. This information may be of considerable value in studies of primate evolution and in assessing their biological affinities and even their migratory patterns. This study also has provided some guidelines with regard to the root canal system in orangutan for dental treatment, particularly during endodontic therapy. It is therefore necessary to have proper radiological or imaging investigations prior to any dental treatment of an orangutan.

\section{Conflict of Interests}

None of the authors of this paper has a financial or personal relationship with other people or organisations that could inappropriately influence or bias the content of the paper.

\section{Acknowledgments}

The authors wish to record their deepest appreciation to Zoo Negara (especially Dr. Mat Naim Ramli, the veterinarian) for permitting them to scanning the orangutan skulls. We are also indebted to dental radiographers, Suziela Zamshi, Zakiah Zakaria, and Nurul Hidayah Abu Bakar, for their assistance. Lastly The authors are grateful to the Ministry of Higher Education, Malaysia, for providing a Grant (UM.C/ HIR/MOHE/DENT/19) for this alternative experience of working with orangutan skulls to understand their dentition better.

\section{References}

[1] J. R. Grehan and J. H. Schwartz, "Evolution of the second orangutan: phylogeny and biogeography of hominid origins," Journal of Biogeography, vol. 36, no. 10, pp. 1823-1844, 2009.

[2] K. S. Warren, E. J. Verschoor, S. Langenhuijzen et al., "Speciation and intrasubspecific variation of Bornean orangutans, Pongo pygmaeus pygmaeus," Molecular Biology and Evolution, vol. 18, no. 4, pp. 472-480, 2001.

[3] J. Mackinnon, "The behaviour and ecology of wild orangutans (Pongo pygmaeus)," Animal Behaviour, vol. 22, no. 1, pp. 3-74, 1974.

[4] J. Courtenay, C. Groves, and P. Andrews, "Inter- or intra-island variation? An assessment of the differences between Bornean and Sumatran orang-utans," in Orangutan Biology, J. H. Schwartz, Ed., Oxford University Press, Oxford, UK, 1988.

[5] T. M. Smith, A.-M. Bacon, F. Demeter et al., "Dental tissue proportions in fossil orangutans from mainland Asia and Indonesia," Human Origins Research, vol. 1, article el, 2011.

[6] A. Uchida, "Variation in tooth morphology of Pongo pygmaeus," Journal of Human Evolution, vol. 34, no. 1, pp. 71-79, 1998.
[7] T. M. Smith, K. Kupczik, Z. MacHanda, M. M. Skinner, and J. P. Zermeno, "Enamel thickness in Bornean and Sumatran orangutan dentitions," American Journal of Physical Anthropology, vol. 147, no. 3, pp. 417-426, 2012.

[8] A. B. Taylor, "Feeding behavior, diet, and the functional consequences of jaw form in orangutans, with implications for the evolution of Pongo," Journal of Human Evolution, vol. 50, no. 4, pp. 377-393, 2006.

[9] E. R. Vogel, J. T. van Woerden, P. W. Lucas, S. S. Utami Atmoko, C. P. van Schaik, and N. J. Dominy, "Functional ecology and evolution of hominoid molar enamel thickness: pan troglodytes schweinfurthii and Pongo pygmaeus wurmbii," Journal of Human Evolution, vol. 55, no. 1, pp. 60-74, 2008.

[10] S. A. Wich, S. S. Utami-Atmoko, T. Mitra Setia, S. Djoyosudharmo, and M. L. Geurts, "Dietary and energetic responses of Pongo abelii to fruit availability fluctuations," International Journal of Primatology, vol. 27, no. 6, pp. 1535-1550, 2006.

[11] R. N. M. Feeney, J. P. Zermeno, D. J. Reid et al., "Enamel thickness in Asian human canines and premolars," Anthropological Science, vol. 118, no. 3, pp. 191-198, 2010.

[12] T. M. Smith, A. J. Olejniczak, L. B. Martin, and D. J. Reid, "Variation in hominoid molar enamel thickness," Journal of Human Evolution, vol. 48, no. 6, pp. 575-592, 2005.

[13] J. E. Scott, C. M. Schrein, and J. Kelley, "Beyond Gorilla and Pongo: alternative models for evaluating variation and sexual dimorphism in fossil hominoid samples," American Journal of Physical Anthropology, vol. 140, no. 2, pp. 253-264, 2009.

[14] G. T. Schwartz and M. C. Dean, "Sexual dimorphism in modern human permanent teeth," American Journal of Physical Anthropology, vol. 128, no. 2, pp. 312-317, 2005.

[15] D. A. Fagan and P. T. Robinson, "Endodontic surgery for treatment of a fistulated molar abscess in an orangutan," Journal of the American Veterinary Medical Association, vol. 173, no. 9, pp. 1141-1144, 1978.

[16] B. T. Szabo, L. Pataky, R. Mikusi, P. Fejerdy, and C. Dobo-Nagy, "Comparative evaluation of cone-beam CT equipment with micro-CT in the visualization of root canal system," Annali dell'Istituto Superiore di Sanita, vol. 48, no. 1, pp. 49-52, 2012.

[17] M. K. Nair and U. P. Nair, "Digital and advanced imaging in endodontics: a review," Journal of Endodontics, vol. 33, no. 1, pp. $1-6,2007$.

[18] K. Purmal and P. Nambiar, "Restorative dental treatment of a canine tooth in a Bornean orang utan," Journal of Veterinary Dentistry, vol. 26, no. 1, pp. 36-39, 2009.

[19] S. J. Nelson and M. M. Ash, Wheeler's Dental Anatomy, Physiology, and Occlusion, WB Saunders, Philadelphia, Pa, USA, 9th edition, 2010.

[20] J. I. Ingle, L. K. Bakland, and J. C. Baumgartner, Ingle's Endodontics, BC Decker Inc., Ontario, Canada, 6th edition, 2008.

[21] P. E. Mahler, "Molar size sequence in the great apes: gorilla, orangutan, and chimpanzee," Journal of Dental Research, vol. 59, no. 4, pp. 749-752, 1980.

[22] P. D. Gingerich and M. J. Schoeninger, "Patterns of tooth size variability in the dentition of primates," American Journal of Physical Anthropology, vol. 51, no. 3, pp. 457-465, 1979.

[23] A. Nanci, Ed., Ten Cate's Oral Histology: Development, Structure, and Function, CV Mosby, St. Louis, Mo, USA, 2003.

[24] L. Cocks, "Factors influencing the well-being and longevity of captive female orangutans," International Journal of Primatology, vol. 28, no. 2, pp. 429-440, 2007. 
[25] F. Vertucci, A. Seelig, and R. Gillis, "Root canal morphology of the human maxillary second premolar," Oral Surgery Oral Medicine and Oral Pathology, vol. 38, no. 3, pp. 456-464, 1974.

[26] F. J. Vertucci, "Root canal morphology and its relationship to endodontic procedures," Endodontic Topics, vol. 10, pp. 3-29, 2005. 


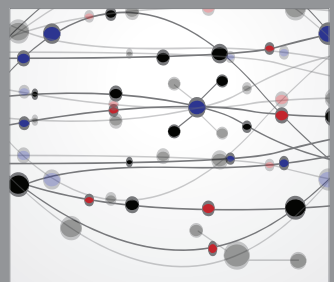

The Scientific World Journal
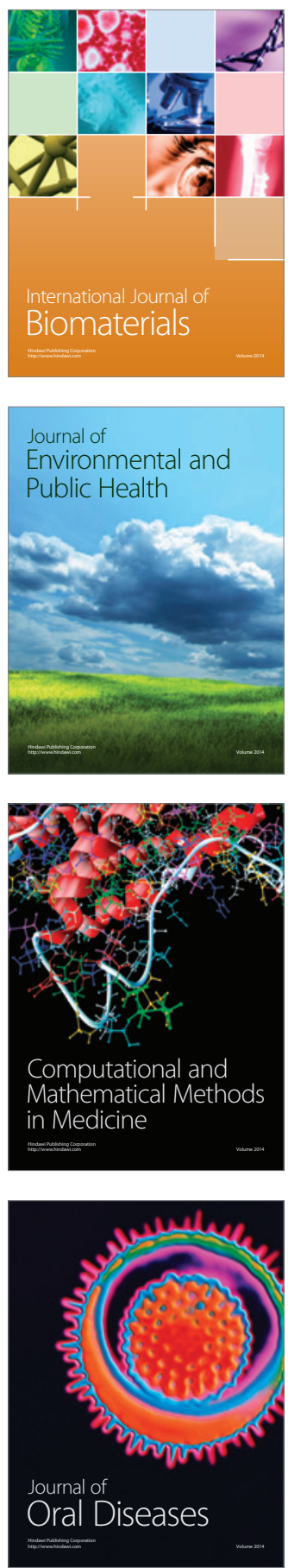
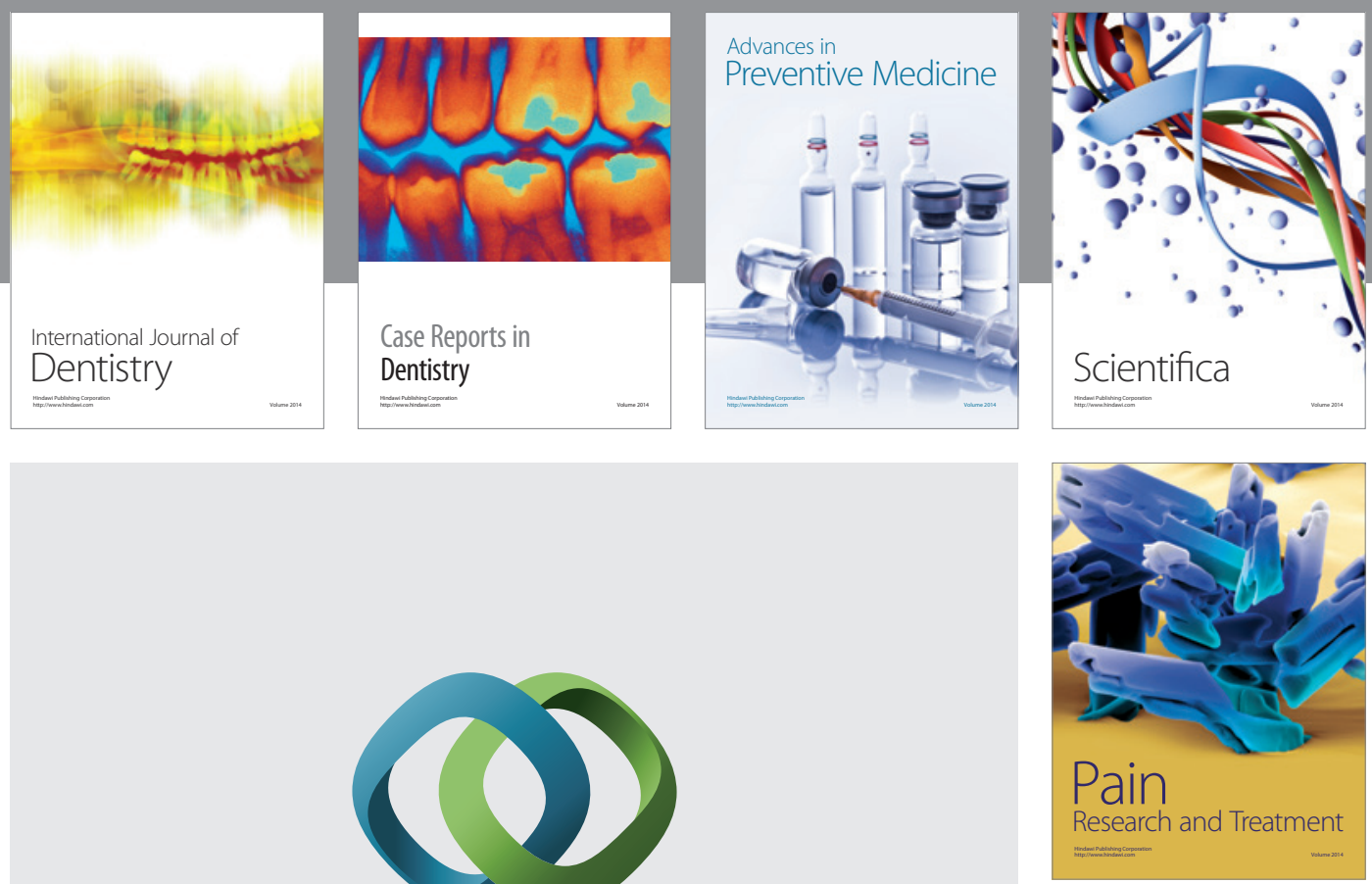

\section{Hindawi}

Submit your manuscripts at

http://www.hindawi.com
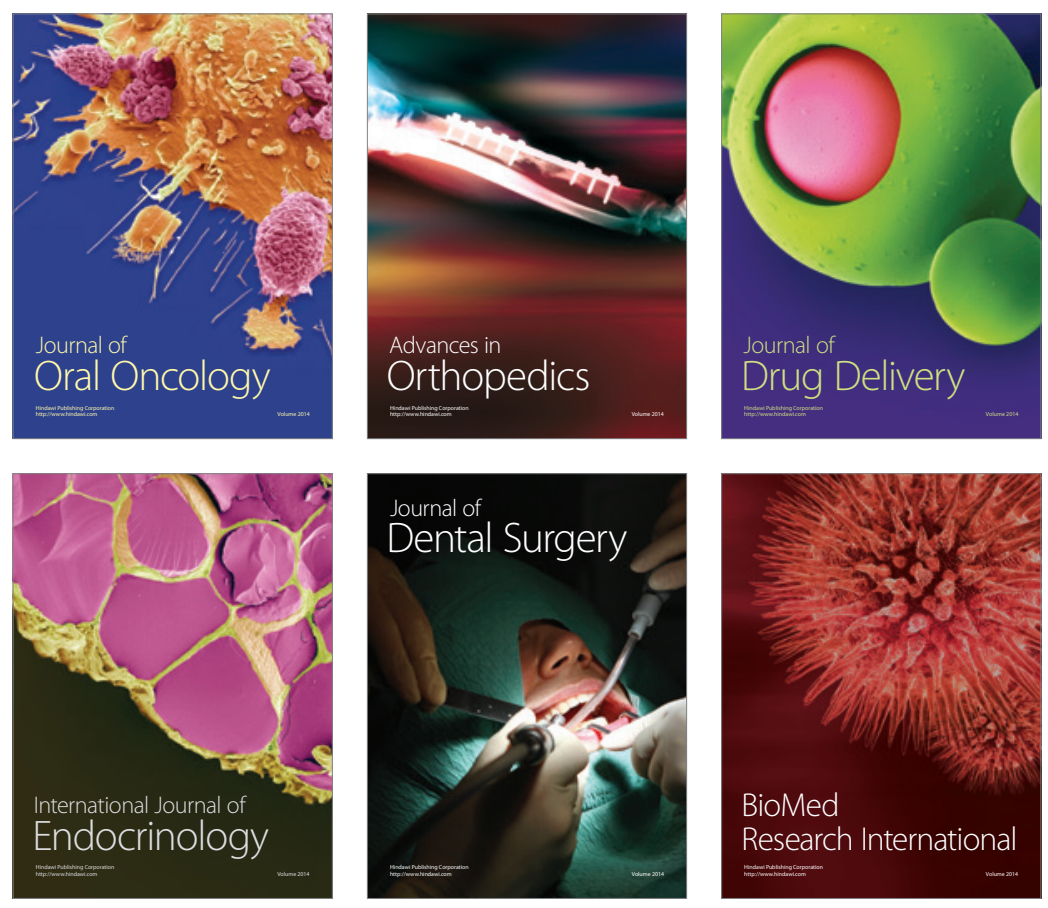

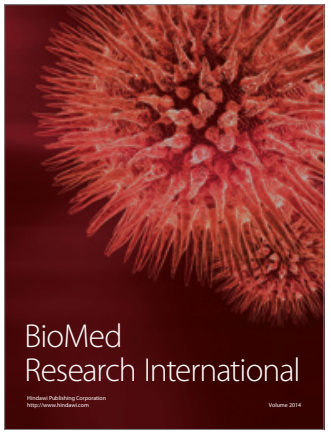

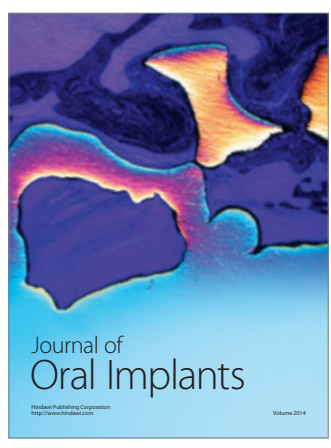
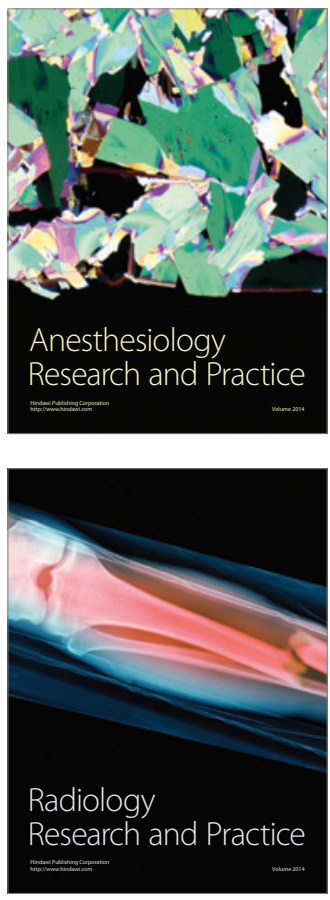